\title{
OXYGEN NON-STOICHIOMETRY IN PEROVSKITIC CATALYSTS: IMPACT ON ACTIVITY FOR THE FLAMELESS COMBUSTION OF METHANE
}

\author{
Ilenia Rossetti ${ }^{\star}$, Cesare Biffi, Lucio Forni \\ Dip. Chimica Fisica ed Elettrochimica, Università degli Studi di Milano \\ v. C. Golgi, 33, I-20133 Milano, Italy
}

\begin{abstract}
Perovskite-like $\mathrm{LaBO}_{3}$ catalysts $(\mathrm{B}=\mathrm{Co}, \mathrm{Mn}, \mathrm{Fe})$, prepared by flame pyrolysis, and doped with $\mathrm{Ce}, \mathrm{Sr}$ or with small amounts of $\mathrm{Pd}$ or $\mathrm{Pt}$ were used for the flameless combustion of methane. The effect of the dopants on the reducibility of the B metal ion has been analysed comparatively, trying to correlate this parameter with catalytic activity. The higher the $\mathrm{B}^{3+}$ ion reducibility, the lower was the light off temperature of the reaction. However, the correlation with the temperature of half conversion revealed that a too high reducibility of the catalyst depressed the second step of the Mars-van Krevelen reaction mechanism, i.e. the reoxidation of active site.
\end{abstract}

The quantitative elaboration of the TPR pattern allowed to determine oxygen nonstoichiometry, at least for the $\mathrm{LaCoO}_{3}$ based samples. Furthermore, the available oxygen amount was correlated to catalytic activity.

Keywords: Temperature programmed desorption; Temperature programmed reduction; TPD; TPR; Perovskites; Catalytic combustion.

\footnotetext{
*Corresponding author. Fax. +39-02-50314300; e-mail: ilenia.rossetti@unimi.it
} 


\section{INTRODUCTION}

$\mathrm{LaBO}_{3}$ catalysts have been deeply investigated for their potentialities for fuel cells, for energy conversion and pollution abatement, their performance being tightly bound to oxygen mobility through the lattice [1-4]. Recently, we have reported activity data of a set of perovskite-like catalysts, characterised by different composition and/or by the different preparation methods [5-10]. Several questions however remained still unanswered, such as the different effect of dopants (either as substitutes for La or as added noble metals), depending on the B-metal ion. In addition, different preparation methods led to more or less variable catalyst performance $[5,7,9]$, not always amenable to surface area difference. Indeed, the high temperature activity of perovskitic catalysts is based on a Mars-van Krevelen mechanism $[4,11]$, in turn dependent on the redox cycle of the $B$ metal ion. Therefore, catalytic performance should be correctly compared by checking possible differences from this point of view.

The main purpose of this work was then to compare the activity for the catalytic flameless combustion of methane with the oxygen release properties of some lanthanumbased perovskites. The latter property was determined by temperature programmed analysis. In particular, thermal release of oxygen or chemical reduction of the B metal ion were tested under inert or $\mathrm{H}_{2}$ atmosphere (TPD and TPR analysis, respectively). The samples differed as for the nature of the B metal ion, the presence or absence of dopants of different nature as substitutes for La, or the addition of small amounts of noble metals.

\section{2 - EXPERIMENTAL}

\section{1 - Catalyst preparation}

The samples were prepared by flame-pyrolysis (FP), a technique extensively described elsewhere $[7,8,9]$. All the solutions to be burned were prepared by dissolving 
in propionic acid the salts of proper metal ions (purity always higher than $99 \%$ ), in suitable concentration: $\quad \mathrm{La}\left(\mathrm{CH}_{3} \mathrm{COO}\right)_{3} \cdot 2 \mathrm{H}_{2} \mathrm{O}, \quad \mathrm{Mn}\left(\mathrm{CH}_{3} \mathrm{COO}\right)_{2} \cdot 4 \mathrm{H}_{2} \mathrm{O}, \quad \mathrm{Fe}(\mathrm{AcAc})_{3} \quad(\mathrm{AcAc}=$ acetylacetonate), $\quad \mathrm{Co}\left(\mathrm{CH}_{3} \mathrm{COO}\right)_{2} \cdot 4 \mathrm{H}_{2} \mathrm{O}, \quad \mathrm{Sr}\left(\mathrm{CH}_{3} \mathrm{COO}\right)_{2}, \quad \mathrm{Ce}\left(\mathrm{CH}_{3} \mathrm{COO}\right)_{3}, \quad \mathrm{Pd}\left(\mathrm{CH}_{3} \mathrm{COO}\right)_{2}$, $\operatorname{Pt}(\mathrm{AcAc})$ 2. The precursors solution was fed $(2.2 \mathrm{ml} / \mathrm{min})$ to the FP burner together with oxygen (5 NL/min) and the pressure drop through the nozzle was usually set to $1.5 \mathrm{bar}$, if not else specified.

The burner consists of a capillary tube (inner diameter $0.6 \mathrm{~mm}$ ) ending in the centre of a vertical nozzle and connected with a syringe pump (Harvard, mod. 975), to feed the precursors solution. The nozzle is co-fed with oxygen (SIAD, purity 99.95\%), which is used both as oxidant and as dispersing agent. This leads to the formation of finely dispersed droplets of solution. The central flame is ignited and supported by a ring of twelve premixed $\mathrm{O}_{2}+\mathrm{CH}_{4}$ (SIAD, purity $99.0 \%$ ) flamelets. Gas flow rate was controlled by means of MKS Instruments (mod. 1259C) mass flowmeters, governed by a MKS Instruments (mod. 247 C) control unit. Oxygen discharge velocity can be varied at fixed feeding rate and by adjusting the pressure drop across the nozzle. Calibrated manometers allowed to control the oxygen inlet pressure. A further ring of small air feeding nozzles allowed to keep an oxidising atmosphere around the burner and helped in conveying the product to the powder collection section. The latter consists of a cylindric electrostatic precipitator, based on a multipin effluviator, surrounded by a coaxial collector, maintained at a $10 \mathrm{kV}$ potential difference. The system allowed to recover ca. $80 \%$ of the produced powder.

\section{2 - Catalyst characterisation}

XRD analysis has been carried out by means of a Philips PW3020 powder diffractometer, by selecting the Ni-filtered $\mathrm{Cu} \mathrm{K}_{\alpha}$ radiation $(\lambda=0.15148 \mathrm{~nm})$ and using a monochromator on the diffracted beam. The diffractograms have been compared with literature data for phase recognition [12]. $N_{2}$ adsorption/desorption isotherms were 
collected by means of a Micromeritics ASAP2010 instrument, after outgassing the sample overnight at $300^{\circ} \mathrm{C}$. Scanning electron microscopy (SEM) analysis was carried out on a LEICA LEO 1420 instrument, equipped for EDS analysis. Thermogravimetric analysis (TGA) was performed by means of a Perkin Elmer TGA7 apparatus, by heating the sample in air by $10^{\circ} \mathrm{C} / \mathrm{min}$ up to $800^{\circ} \mathrm{C}$.

Temperature programmed desorption (TPD) and reduction (TPR) were carried out on ca. $0.15 \mathrm{~g}$ of catalyst, loaded into a continuous, tubular quartz microreactor, heated by an electric furnace, controlled by an Eurotherm 2408 TRC. The composition of the outlet gas was continuously monitored by means of a quadrupolar mass spectrometer (MS) (MKS, PPT Residual Gas Analyser). TPD of pre-adsorbed $\mathrm{O}_{2}$ was carried out in 30 $\mathrm{Ncm}^{3} /$ min flowing He (purity $\geq 99,9999$ vol\%), after pretreatment at $800^{\circ} \mathrm{C}$ in He for $1 \mathrm{~h}$, saturation at $750^{\circ} \mathrm{C}$ for 1 hour in $20 \mathrm{Ncm}^{3} / \mathrm{min}$ flowing air (purity $\geq 99,9995 \mathrm{vol} \%$ ) and cooling down to $50^{\circ} \mathrm{C}$, always in flowing air. Prior to desorption the sample was equilibrated in $30 \mathrm{Ncm}^{3} / \mathrm{min}$ flowing $\mathrm{He}$ at $50^{\circ} \mathrm{C}$ and then heated $\left(10^{\circ} \mathrm{C} / \mathrm{min}\right)$ up to $800^{\circ} \mathrm{C}$. The TPR experiment was carried out, after pre-saturation in $20 \mathrm{Ncm} 3 / \mathrm{min}$ flowing air at $750^{\circ} \mathrm{C}$ for $1 \mathrm{~h}$, by feeding continuously $30 \mathrm{Ncm}^{3} / \mathrm{min}$ of a 10 vol\% $\mathrm{H}_{2}$ in He gas mixture, while heating $\left(10^{\circ} \mathrm{C} / \mathrm{min}\right)$ from $50^{\circ} \mathrm{C}$ up to $800^{\circ} \mathrm{C}$.

The same procedure has been repeated under the same conditions in a parallel device equipped with thermal conductivity detector (TCD) to quantify hydrogen uptake after proper calibration with $\mathrm{CuO}$.

\section{3 - Catalytic activity testing}

Activity tests were carried out by means of a continuous quartz tubular reactor on ca. $0.15 \mathrm{~g}$ of catalyst, pelletized, ground and sieved to $0.15-0.25 \mathrm{~mm}$ particles. Prior to each run, the catalyst was activated in flowing air $\left(20 \mathrm{Ncm}^{3} / \mathrm{min}\right)$, while increasing temperature by $10^{\circ} \mathrm{C} / \mathrm{min}$ up to $600^{\circ} \mathrm{C}$, then kept for $1 \mathrm{~h}$. The activity tests were carried out 
by feeding a mixture composed of 0.34 vol. $\% \mathrm{CH}_{4}, 33.3$ vol. $\%$ air, He balance, while increasing temperature by $10^{\circ} \mathrm{C} / \mathrm{min}$ from $200^{\circ} \mathrm{C}$ up to $600^{\circ} \mathrm{C}$. Gas flow rate was regulated by means of mass flow controllers (Brooks Instruments, mod. 5850) governed by a control unit (Brooks, mod. 0154). The total gas flow rate was $30 \mathrm{Ncm}^{3} / \mathrm{min}$. The outcoming gas was analysed in line by means of the quadrupolar mass spectrometer, selecting proper mass fragments.

\section{3 - RESULTS AND DISCUSSION}

The composition of the catalysts prepared and some relevant physical chemical properties are collected in Table 1. The specific surface area (SSA) of the as prepared samples always ranged between 40 and $80 \mathrm{~m}^{2} / \mathrm{g}$. The dependence of surface area on the pressure drop across the nozzle, i.e. on the residence time into the hottest part of the flame, has been already discussed [7]. It has been confirmed here when considering two selected samples (Table 1) prepared by imposing a lower pressure drop, i.e. 0.4 instead of 1.5 bar. This entrained a lower oxygen discharge velocity, with consequent higher residence time and therefore a bit higher particle sintering. The increase of particle size may further enhance the residence time into the flame.

The particle size was always lower than $60 \mathrm{~nm}$ for the FP-prepared samples, with rather uniform distribution in all cases, as exemplified in Fig.1.

TGA analysis showed that unburnt residua were always lower than $5 \mathrm{wt} \%$. In most cases the weight loss, including some humidity and residual solvent, mainly occurred between 100 and $300^{\circ} \mathrm{C}$ (Fig.2). Sometimes a high temperature weight loss has been observed, due to carbonate species decomposing around $500-600^{\circ} \mathrm{C}$. This was especially relevant for $\mathrm{Sr}$ doped samples, indicating the presence of stable carbonates. However, 
their decomposition temperature is compatible with the catalyst activation conditions preceding the activity tests.

$\mathrm{XRD}$ analysis always confirmed the presence of a single phase, corresponding to the nominal one, as compared with reference data [12]. When comparing the XRD patterns of undoped $\mathrm{ABO}_{3}$ catalysts (Fig. 3a), a shift towards higher $2 \theta$ values has been observed with decreasing the $\mathrm{B}$ metal ionic radius, i.e. when passing from $\mathrm{Mn}$ to $\mathrm{Fe}$ and Co. Interestingly, $\mathrm{LaCoO}_{3}$ showed much broader reflections and their typical splitting, characteristic of the rhombohedral phase, was not observed for the Ce-doped sample, assuming a pseudo-cubic structure. Reflection splitting started instead to be evident for the Sr-doped sample (Fig. 3b). Particular care was put on phase identification in the case of doped samples, to check for substituent insertion into the framework. No evidence of a separate second phase has been ever observed.

In the case of doping with noble metals, no evidence of different phases has been observed, as expected due to their very low loading. However, a visible shift towards higher $2 \theta$ values can be observed in Fig. $3 c$ for the noble-metal-doped Mn-based samples and similar results were obtained for the Co-based ones, indicating dopant incorporation into the lattice, at least in part [13].

\section{1 - Oxygen release properties}

TPD of preadsorbed oxygen can be used as a tool to evaluate the spontaneous reduction of the B metal ion. It is well known [14-18] that two desorption peaks can be usually observed for La-based perovskites, denoted as $\alpha$ and $\beta$. The former is usually found at relatively low temperature $\left(<500^{\circ} \mathrm{C}\right)$ and is ascribed to oxygen release from the surface, whereas the latter occurs at higher temperature, depending on the stability of the $\mathrm{BO}_{x}$ oxide. 
The as-synthesised $\mathrm{LaFeO}_{3}$ did not show any peak in the whole temperature range. This behaviour has been already reported $[19,20]$, although the appearance of TPD peaks has been described elsewhere [21] and attributed to $\mathrm{Fe}^{4+}$ reduction in the case of $\mathrm{Ca}$ doped samples, or anyway to oxygen-rich samples $[22,23]$. Only after calcination at $500^{\circ} \mathrm{C}$ or $800^{\circ} \mathrm{C}$, a very faint bump appeared at ca. $650^{\circ} \mathrm{C}$ with the present catalysts. The latter feature became significant, though poorly intense, only after the addition of $0.5 \mathrm{wt} \% \mathrm{Pd}$, which led to the formation of a double peak (maxima at 630 and $730^{\circ} \mathrm{C}$, respectively). This indicates that the spontaneous release of oxygen from $\mathrm{LaFeO}_{3}$ (likely $\mathrm{Fe}^{4+}$ reduction to $\mathrm{Fe}^{3+}$ ) can be enhanced by partial sintering in air and mostly by the addition of a small amount of noble metal, which can be partly incorporated in the framework as $\mathrm{Pd}^{2+}$. As for the extent of sample sintering, it should be noticed that no significant difference in the TPD patterns has been observed when synthesising samples with different pressure drop across the burner nozzle. As already discussed [7], the higher the pressure drop, the lower is the residence time into the flame and hence the lower is sample sintering. The latter phenomenon is anyway limited, as visible from the differences of catalyst surface area (Table 1), and only a prolonged calcination (exemplified for sample $\mathrm{LaFeO}_{3}$, only) leads to the appearance of a peak in the TPD pattern.

By contrast, $\mathrm{LaCoO}_{3}$ showed a steep $\beta$ peak at ca. $730-750^{\circ} \mathrm{C}$, becoming broader upon Pd addition. Interestingly, catalyst formulations with mixed B metal ions (see e.g. $\mathrm{LaCoy}_{\mathrm{Fe}}(1-\mathrm{y}) \mathrm{O}_{3}+0.5 \mathrm{wt} \% \mathrm{Pd}$ ) showed intermediate behaviour, i.e. when adding Co to the $\mathrm{LaFeO}_{3}$ the high-temperature peak started broadening towards higher temperature and vice versa for $\mathrm{Fe}$ addition to $\mathrm{LaCoO}_{3}$. This is a peculiar feature, confirming the intimate mixing of the couple of B metals, as reported for similar La-Mn-Co formulations [24].

As for $\mathrm{Ce}$ - and $\mathrm{Sr}$-doped $\mathrm{LaCoO}_{3}$, no significant low temperature oxygen release has been observed, while the $\beta$ peak slightly shifted $\left(\mathrm{ca} .20^{\circ} \mathrm{C}\right)$ towards lower temperature by $\mathrm{Sr}$ addition and towards higher temperature by $\mathrm{Ce}$ addition. Sr likely leads to the 
formation of oxygen vacancies. Indeed, the formation of $\mathrm{Co}^{4+}$ ions, though they can be stabilised by the perovskitic lattice as observed by Berry et al. [25], would have led to oxygen release at much lower temperature in the TPD pattern, but a low temperature peak corresponding to a $\mathrm{Co}^{4+} \rightarrow \mathrm{Co}^{3+}$ reduction was not observed here. The formation of oxygen vacancies would enhance oxygen mobility, favouring oxygen transport towards the surface. By contrast, when adding $\mathrm{Ce}^{4+}$ a more difficult $\mathrm{Co}^{3+}$ reduction is expected, since Co can be already partially present in a lower valence state and the formation of further oxygen vacancies becomes unlikely.

The normalised TPD patterns of the Mn-based perovskites are reported in Fig. 4. An intense $\beta$ peak is evident for every sample, with the same onset at ca. $550^{\circ} \mathrm{C}$, irrespectively of the dopant substitution degree. By contrast, the low temperature $\alpha$ peak showed deeply influenced by La substituents. Indeed, no low-temperature oxygen release was evident for $\mathrm{LaMnO}_{3}$, indicating the absence of interstitial oxygen and therefore inherently confirming the nominal sample stoichiometry. This is rather surprising, since this material commonly shows non-stoichiometric composition, which is inherently useful for many applications. Recent results ${ }^{1}$ confirmed the absence of overstoichiometric oxygen in FP-prepared $\mathrm{LaMnO}_{3}$ at difference with a sample prepared by the sol-gel technique. The reason may be searched in the flash calcination at much higher temperature, that limits over-oxidation of part of $\mathrm{Mn}^{3+}$ to $\mathrm{Mn}^{4+}$.

Sr addition induced the formation of a $\alpha$ peak centred between 300 and $400^{\circ} \mathrm{C}$, whose intensity increased steeply with dopant concentration. This can be explained by the formation of $\mathrm{Mn}^{4+}$ ions, progressively reducing to $\mathrm{Mn}^{3+}$ when increasing temperature with formation of oxygen vacancies. This increases the mobility of bulk oxygen towards the surface [21], though the further accommodation of interstitial oxygen cannot be excluded.

\footnotetext{
${ }^{1}$ Yet unpublished data: "Effective Ag doping and resistance to sulphur poisoning of La-Mn perovskites for the catalytic flameless combustion of methane", O. Buchneva, I. Rossetti, C. Oliva, M. Scavini, S. Cappelli, B.

Sironi, M. Allieta, A. Kryukov, L. Forni, J. Mater.Chem., submitted.
} 
Finally, the TPD pattern of $\mathrm{La}_{0.9} \mathrm{Ce}_{0.1} \mathrm{MnO}_{3}$ is characterised by two low temperature peaks, likely indicating an overstoichiometric oxygen content. The presence of multiple peaks has been indeed ascribed to $a+\delta$ non-stoichiometry [26], since the former peak can be ascribed to $\mathrm{Mn}^{4+}$ reduction to $\mathrm{Mn}^{3+}$, while the latter either to $\mathrm{Ce}^{4+}$ to $\mathrm{Ce}^{3+}$ or to partial $\mathrm{Mn}^{3+}$ to $\mathrm{Mn}^{2+}$ reduction. Pure $\mathrm{CeO}_{2}$ reduction is usually reported to occur at much higher temperature [27], but $\mathrm{Ce}^{3+}$ can be accommodated into the perovskitic lattice, so both reactions are likely to occur. Noble metals addition in this case did not induce modifications to the TPD pattern.

\section{$3.2-B$ ion reducibility}

TPR analysis is a common characterisation method to assess the reducibility of an oxide, as well as to quantify the oxygen availability. Due to poor signal-to-noise ratio for $\mathrm{m} / \mathrm{z}=2$ ( $\mathrm{H}_{2}$ uptake), the specular $\mathrm{m} / \mathrm{z}=18$ signal $\left(\mathrm{H}_{2} \mathrm{O}\right.$ formation) is reported in our TPR-MS patterns.

The comparison between the reduction patterns of undoped samples is reported in Fig. 5a. The first reduction peak can be ascribed to the reduction of $\mathrm{B}^{3+}$ to $\mathrm{B}^{2+}$. Further reduction to metallic $\mathrm{B}^{0}$ can occur at higher temperature. $\mathrm{Co}^{3+}$ showed the most reducible ion, followed in descending order by $\mathrm{Fe}^{3+}$ and $\mathrm{Mn}^{3+}$, for both of which only the onset of the second reduction peak was observed in the temperature range investigated. It is also worth noticing that $\mathrm{LaFeO}_{3}$ and mostly $\mathrm{LaMnO}_{3}$ show very broad reduction peaks, indicating the presence of different oxygen species, some of them less prone to react with $\mathrm{H}_{2}$. Shoulders in this first reduction feature could also be attributed to the presence of $\mathrm{B}^{4+}$ reducing to $\mathrm{B}^{3+}$ or directly to $\mathrm{B}^{2+}$ [23]. A higher reducibility of $\mathrm{B}^{3+}$ is evident for samples prepared with lower pressure drop across the nozzle, indicating that a slightly higher sintering (i.e. higher order) induces higher reducibility. Furthermore, the first reduction peak becomes a little sharper, so that a higher order leads to more energetically uniform 
oxygen species. This should be compared with what reported by Isupova et al. [28], who found that the tuning of B-O interaction strength was also correlated to the concentration of phase boundaries, a higher reducibility being expected with increasing their concentration. The latter is confirmed by some FP-prepared Pr-doped nanostructured samples, which showed much more reducible with respect to sintered catalysts prepared by sol-gel and characterised by negligible SSA $\left(<2 \mathrm{~m}^{2} / \mathrm{g}\right)$ and much higher crystal size. The reason of the apparent contrast between the "sintering" effect due to FP residence time (pressure drop) and extensive sintering by post-synthesis calcination can be found in XRD data. The latter show that in spite of a bit lower surface area and bigger particle size, no dramatic increase of crystal size can be observed by comparing samples prepared with different pressure drop. This can be explained by an increase of crystal boundaries concentration in larger particles, responsible of the slightly increased catalyst reducibility.

$\mathrm{Pd}$ addition to $\mathrm{LaFeO}_{3}$ led to a $60^{\circ} \mathrm{C}$ shift towards lower temperature of the first reduction peak, without affecting the second one. The same behaviour has been shown by $\mathrm{LaMnO}_{3}$, but with much larger shift $\left(\mathrm{ca} .200^{\circ} \mathrm{C}\right)$, upon both $\mathrm{Pd}$ and $\mathrm{Pt}$ addition. $\mathrm{A}$ considerably deeper modification of the reduction pattern occurred upon $\mathrm{Pd}$ addition to $\mathrm{LaCoO}_{3}$ (Fig. 5b). Indeed, a new low-temperature peak added to the former one (occurring at the same temperature with respect to the undoped sample). Though MS analysis is hard to be interpreted quantitatively, it seems unlikely that a so intense reduction feature can be ascribed to $\mathrm{PdO}_{x}$ reduction, due to its very low amount. Furthermore, no evidence of so structured features was present for $\mathrm{Pd}$ doped $\mathrm{Mn}$ and Fe-based samples or $\mathrm{LaCo}_{0.1} \mathrm{Fe}_{0.9} \mathrm{O}_{3}$. In addition, at difference with the latter samples, $\mathrm{Pd}$ doping of $\mathrm{LaCoO}_{3}$ led to a decrease of the $\mathrm{Co}^{2+}$ reduction temperature, whereas the latter increased again with $\mathrm{LaCo}_{0.9} \mathrm{Fe}_{0.1} \mathrm{O}_{3}$ and even more for $\mathrm{LaCo}_{0.1} \mathrm{Fe}_{0.9} \mathrm{O}_{3}$. These mixed $\mathrm{B}$-metal formulations confirmed to have intermediate oxygen release properties with respect to the parent simpler samples, as discussed also in the previous section. 
The effect of $\mathrm{Pd}$ addition to $\mathrm{LaCoO}_{3}$ on Co reducibility has been discussed by other authors [13, 29-31]. A high dispersion of metallic Pd would lead to $\mathrm{H}_{2}$ spill-over and to a lower $\mathrm{Co}^{3+-} \mathrm{O}$ "bond strength", so enhancing $\mathrm{Co}^{3+}$ reducibility. This hypothesis is supported by our data and integrated by the observed lower effect for Fe- and the negligible one for Mn-based samples, which can explain the different effect of Pd on catalytic activity of manganites and cobaltites (vide infra). Furthermore, the presence of multiple peaks can be interpreted by charge transfer from the metal to the perovskite lattice modulating the Co-O interaction in proximity of $\mathrm{Pd}$ particles. However, $\mathrm{Pd}$ is likely in framework position in our samples, according to XRD data (Fig. $3 c$, absence of $\mathrm{PdO}$ reflection at $2 \theta=33^{\circ}$ and shifting of the reflections towards higher $2 \theta$ values) and TPR patterns (absence of a reduction peak at $100^{\circ} \mathrm{C}$, attributed to extraframework $\mathrm{PdO}$ [13]). The reduction of $\mathrm{PdO}$ in lattice position is expected at $\mathrm{ca} .200^{\circ} \mathrm{C}$, leading to very dispersed $\mathrm{Pd}$, with the mentioned effect on the surrounding environment.

Pt addition induced some peculiar reduction properties. Indeed, it did not affect the reduction temperature of $\mathrm{Co}^{3+}$, while decreasing by ca. $70^{\circ} \mathrm{C}$ that of $\mathrm{Co}^{2+}$. By contrast, in the case of Pt-doped $\mathrm{LaMnO}_{3}$ an identical reduction pattern with respect to the $\mathrm{Pd}$ containing sample was obtained.

The TPR patterns of $\mathrm{Ce}$ - and Sr-doped cobaltites are reported in Fig. 6a. Both substituents induce a lower reducibility of $\mathrm{Co}^{3+}$, but a higher one for $\mathrm{Co}^{2+}$. $\mathrm{Sr}$ doping provokes oxygen vacancies formation, also according to the results of TPD analysis, so decreasing the $\mathrm{Co}^{3+}$ reducibility. On the other hand, $\mathrm{Ce}^{4+}$ insertion in the perovskite lattice could induce a partial reduction of $\mathrm{Co}^{3+}$ to $\mathrm{Co}^{2+}$, leading to the same effect on Co reducibility. Furthermore, a shoulder is evident in the first reduction peak, especially for the Sr doped sample. This can be ascribed to the presence of energetically heterogeneous $\mathrm{Co}^{3+}$ species. As for the second reduction peak, both substituents induce an easier $\mathrm{Co}^{2+}$ reduction. This is in line with a lower stability of the cobaltite lattice upon doping. Indeed, 
the addition of ions with different ionic radius causes stress and deformation of the crystal structure. This is particularly relevant with high dopant concentration, particularly when it induces the formation of oxygen vacancies, which create voids and local reorganisation. Therefore, the system is less prone to release oxygen at low temperature, but the overall structure is less stable, leading to complete reduction at lower temperature, with consequent collapsing of the perovskite framework. Something similar has been reported elsewhere $[4,11,24]$, confirming a lower resistance to complete reduction of cobaltite in the presence of excess oxygen vacancies.

As for manganites, the selected dopants did not lead to a modification of $\mathrm{Mn}^{3+}$ or $\mathrm{Mn}^{2+}$ reduction temperatures, with the exception of $\mathrm{La}_{0.8} \mathrm{Sr}_{0.2} \mathrm{MnO}_{3}$, which showed a much broader reduction pattern and overall lower stability towards reduction. In line with what discussed in the previous paragraph, Ce-doping did not provoke $\mathrm{Mn}$ reduction to $\mathrm{Mn}^{2+}$, but the formation of excess interstitial oxygen, as witnessed by the big area of the first reduction peak and by the presence of a little shoulder, likely due to the reduction of $\mathrm{Ce}^{4+}$ to $\mathrm{Ce}^{3+}$ or of $\mathrm{Mn}^{4+}$ to $\mathrm{Mn}^{3+}$. Sr-doped samples showed a double contribution, which can be ascribed to a $\mathrm{Mn}^{4+}$ to $\mathrm{Mn}^{3+}$ reduction and from the latter to $\mathrm{Mn}^{2+}$. The very broad reduction peaks indicate the presence of energetically non homogeneous ions.

Though mass spectrometry is very sensitive and useful to discriminate the evolution of different species during TPD and TPR, it is not suitable for a reliable quantification of oxygen non-stoichiometry, which is one of the hardest tasks when dealing with these materials. Therefore, some tests have been reproduced by means of an identical apparatus, equipped with a TCD detector, properly calibrated for the quantification of hydrogen uptake. When necessary, peaks deconvolution has been carried out by Lorentzian fitting and the contribution of single reduction features has been considered.

As an example, the results of data elaboration are here reported in detail for $\mathrm{La}_{0.9} \mathrm{Sr}_{0.1} \mathrm{CoO}_{3}$. The TPR-TCD reduction patterns are reported in Fig.7, together with the 
curve fitting results used for the separate integration of the two reduction peaks. $\mathrm{H}_{2}$ uptake can be calculated from peak area upon calibration and assuming that $1 \mathrm{~mol}_{2}$ titrates 1 mol of atomic oxygen. The overall oxygen amount titrated up to $800^{\circ} \mathrm{C}$ was $7.09{ }^{*} 10^{-4}$ mol. From the nominal sample stoichiometry and the catalyst amount loaded in the microreactor, the theoretical total oxygen amount would be $1.49 * 10^{-3} \mathrm{~mol}$. We here introduce the hypothesis that Co was fully reduced to the metallic state under the present conditions, by following the mentioned route: the first reduction peak corresponding to $\mathrm{Co}^{3+}$ to $\mathrm{Co}^{2+}$ reduction. By neglecting the possible reduction of $\mathrm{La}$ and $\mathrm{Sr}$, we could assume as final products $\mathrm{Co}, \mathrm{SrO}$ and $\mathrm{La}_{2} \mathrm{O}_{3}$ [25], though some different residual products have been hypothesised elsewhere [24]. Therefore, we calculated the theoretical residual oxygen amount in the sample after reduction, which corresponded to 7.20 * $10^{-4} \mathrm{~mol}$. The oxygen balance obtained by summing the latter figure with the titrated oxygen amount leads to $1.43 * 10^{-4} \mathrm{~mol}$, lower than the expected from a non-defective oxygen stoichiometry, i.e. from the balance of Sr-induced positive charge decrease else than forming oxygen vacancies. Hence, from these data we can also calculate a rough value of oxygen non stoichiometry, obtaining a sample formula $\mathrm{La}_{0.9} \mathrm{Sr}_{0.1} \mathrm{CoO}_{2.87}$, which seems rather reasonable based on sample composition.

The same elaboration on $\mathrm{La}_{0.9} \mathrm{Ce}_{0.1} \mathrm{CoO}_{3}$ led to some complications due to the need of peak deconvolution for the first reduction feature. Indeed, by comparing the hydrogen uptake relative to the low temperature reduction reactions with the high temperature one and making the same assumptions above reported, in particular neglecting the possibility of $\mathrm{CeO}_{2}$ reduction, the residual oxygen would be $6.61^{*} 10^{-4} \mathrm{~mol}\left(\mathrm{CeO}_{2}+\mathrm{La}_{2} \mathrm{O}_{3}\right)$ to be summed to the overall titrated oxygen $\left(6.77^{*} 10^{-4} \mathrm{~mol}\right)$. This overestimates by ca. $10 \%$ the theoretical amount of oxygen, calculated from the nominal catalyst stoichiometry. The oxygen balance is much better closed when assuming also $\mathrm{CeO}_{2}$ reduction to $\mathrm{Ce}_{2} \mathrm{O}_{3}$. Furthermore, deconvolution of the first reduction feature was best fitted by considering 
three overlapping reduction peaks, centred on ca. 250,350 and $400^{\circ} \mathrm{C}$. By separately integrating those peaks one may notice that the theoretical amount of $\mathrm{H}_{2}$ needed to reduce $\mathrm{Ce}^{4+}$ to $\mathrm{Ce}^{3+}$ perfectly corresponds to the contribution of the third peak. By subtracting the latter, the $\mathrm{H}_{2}$ uptake of the first two peaks is exactly corresponding to half the high temperature peak. This would imply an overstoichiometric oxygen amount corresponding to the formula $\mathrm{La}_{0.9} \mathrm{Ce}_{0.1} \mathrm{CoO}_{3.09}$, rather surprising for cobaltites, which usually do not host interstitial oxygen.

Another representative sample is constituted by $\mathrm{LaCoO}_{3}+\mathrm{Pt} 0.5 \mathrm{wt} \%$, for which a stoichiometric formula of $\mathrm{LaCoO}_{2.97}$ can be calculated by assuming a nominal $\mathrm{PtO}_{2}$ composition. Due to the low $\mathrm{Pt}$ amount it was not possible to resolve its reduction peak in the first TPR feature.

A similar approach has been adopted also for manganites, which however usually do not completely close the high temperature reduction peak within the temperature limits of our apparatus. It was therefore hard to use those data to evaluate oxygen stoichiometry. A qualitative correlation between the overall oxygen titrated and the activity data will be anyway proposed in the next paragraph. Peak deconvolution can be useful also for these samples to address the reduction mechanism of different ion species.

\section{3 - Effect of oxygen release properties on catalytic activity}

A detailed description of the catalytic performance of the present catalysts has been reported elsewhere [10]. In the present work, the activity data will be presented as $\mathrm{T}_{0}$ and $\mathrm{T}_{50}$ (Table 1), which represent the light-off and half-conversion temperatures, respectively. Sometimes, the term Conv 450 will be adopted, representing methane conversion at $450^{\circ} \mathrm{C}$. All these data for every catalyst, irrespectively of its composition, have been compared with the onset and maxima temperatures of both TPD and TPR patterns, searching for 
possible correlations. In case of multiple peaks the procedure was repeated for everyone of them.

No apparent correlation among the presence of a $\alpha$ peak in the TPD pattern and catalytic activity has been noticed. Furthermore, $T_{0}$ showed independent of the onset temperature of the $\beta$ peak, whereas $T_{50}$ slightly increased and Conv ${ }_{450}$ decreased with this parameter. This is not very surprising, since it indicates that a less spontaneous oxygen release limits activity. However, some outliers have been found, since $\mathrm{Sr}$ and $\mathrm{Pd}$ doped samples usually showed different behaviour, being more active than expected form their oxygen release properties. We may underline that TPD experiments may be more suitable to describe oxygen mobility and the kinetics of surface oxygen recombination, whereas TPR procedure is more directly comparable to activity testing.

As for TPR analysis, $T_{0}$ (Table 1) slightly increased with the onset temperature of the low temperature reduction peak, indicating that a higher reducibility is beneficial for the light-off of the reaction. However, when looking at $T_{50}$ and Conv $_{450}$, an increase of the same parameter induced an increase of conversion and a decrease of $T_{50}$, which seem contrasting with the previous observation. A possible interpretation is that the catalytic reaction occurs through a two-steps Mars-van Krevelen mechanism, needing the restoration of the oxidised $B$ metal active site to start a new reaction cycle. This means that if the $\mathrm{B}$ ion is too prone to reduction, the first step of the reaction can be easy (lower light-off temperature), but the second one, i.e. reoxidation, is likely rather slow. Therefore, a good compromise must be found.

The high-temperature reduction peak did not reveal significant, since the different perovskite families here analysed showed markedly different onset temperatures, but similarly high activity. This confirms that the last reduction feature, i.e. $\mathrm{B}^{2+} \rightarrow \mathrm{B}^{0}$ is not significantly involved in the reaction, the redox cycle involving $\mathrm{B}^{2+}$ as lowest oxidation state. 
In order to better address this point, the quantitative data obtained from TPR-TCD patterns have been correlated with the same activity indicators above described. In particular, we have considered the overall oxygen amount titrated in the low temperature peak(s), in the high temperature one(s), as well as the total amount of oxygen titrated. Furthermore, we have employed the results of peak deconvolution to enucleate the contribution of every single reduction event. The latter comparison, however, revealed unsuccessful, in part due to imprecise assessment of the single peaks area, and in part due to the simultaneous cooperation of different reduction reactions. Indeed, when considering the overall amount of oxygen available at low temperature, its increase leads to lower $T_{50}$. The contrary happens for the high temperature reduction peak, though the correlation is less significant (very low slope), the former contribution being dominant. The effect of the total amount of oxygen titrated on activity is exemplified in Fig. 8. A good correlation has been obtained for both the sample families of manganites and cobaltites, with the exception of Pt-doped samples (empty symbols in Fig.8a and $b$ ) that show high activity although their oxygen availability is very low. The present data indicate that the higher is oxygen availability, the higher is catalytic activity. Similar conclusions have been drawn by others on different systems [32]. It should be underlined that, as stated at the end of the previous paragraph, quantitative data on the overall oxygen amount titrated are underestimated for $\mathrm{LaMnO}_{3}$. However, due to the lower dependence of activity data on the second reduction peak a good correlation has been anyway obtained also for those samples.

By excluding the evidenced outliers (Pt containing samples), the linear regression of the data has been carried out by correlating $Y=$ total oxygen titrated $(\mathrm{mol})$ vs. $X=T_{50}\left({ }^{\circ} \mathrm{C}\right)$. The slope was found $(-9.7 \pm 2.6) * 10^{3}$ for the manganite series, with an intercept of $(+$ $4.9 \pm 0.16) * 10^{2}$. In the case of Co-based catalysts the slope was $(-2.1 \pm 0.4) * 10^{4}$ and the intercept $(+5.8 \pm 0.3) * 10^{2}$. These data evidence a better correlation and a higher 
dependence of the temperature of half conversion on oxygen availability for the latter samples series.

As a final remark, Pd doping increased the catalytic activity of Co-based samples, whereas it had the opposite effect on Mn-containing catalysts. This can be explained in terms of its effect in increasing $\mathrm{Co}^{3+}$ reducibility, leaving unaffected the one of $\mathrm{Mn}$ (Fig. $5 b$ and 8).

\section{CONCLUSIONS}

The oxygen release properties of a set of nanostructured catalysts prepared by flame pyrolysis have been correlated with catalytic performance for deep oxidation reactions. Higher reducibility of the $\mathrm{B}^{3+}$ ion is beneficial to decrease the light off temperature, but if its subsequent reoxidation is not sufficiently fast, this can be detrimental for the overall catalyst performance. Quantitative TPR analysis allowed to quantify the oxygen non-stoichiometry and to determine the content of available oxygen. The latter parameter has been correlated to catalytic activity showing that the higher the titrated oxygen amount (in particular referring to the low-temperature reduction feature), the higher is catalytic activity. An exception is represented by Pt-doped samples, which show very high activity though their oxygen release properties were lower than other samples.

\section{ACKNOWLEDGEMENTS}

The authors are indebted to D. Coslovi for TPD-TPR data collection.

\section{REFERENCES}

1. Y.M. Choi, M.E. Lynch, M.C. Lin, M. Liu, J. Phys. Chem. C, 113 (2009) $7290 .$.

2. S. Royer, D. Duprez, S. Kaliaguine, Catal. Today, 112 (2006) 99.

3. I. Rossetti, L. Forni, in "Synthesis, Properties and Applications of Oxide Nanomaterials", J.A. Rodriguez and M. Fernàndez-Garcia, Eds., Wiley, 2007, p. 563.

4. $\quad$ M.A. Peña, J.L.G. Fierro, Chem. Rev., 101 (2001) 1981.

5. E. Campagnoli, A. Tavares, L. Fabbrini, I. Rossetti, Yu. A. Dubitski, A. Zaopo, L. Forni, Appl. Catal. B: Environmental, 55 (2005) 133. 
6. E. Campagnoli, A. Tavares, L. Fabbrini, I. Rossetti, Yu.A. Dubitsky, A. Zaopo, L. Forni, J. Mater. Sci., 41 (2006) 4713.

7. G.L. Chiarello, I. Rossetti, L. Forni, J. Catal., 236 (2005) 251.

8. G.L. Chiarello, I. Rossetti, P. Lopinto, G. Migliavacca, L. Forni, Catal. Today, 117 (2006) 549.

9. G.L. Chiarello, I. Rossetti, P. Lopinto, G. Migliavacca, L. Forni, Appl. Catal. B: Environmental, 72 (2007) 218 (part 1) and 227 (part 2).

10. I. Rossetti, O. Buchneva, C. Biffi, R. Rizza, Appl. Catal. B: Environmental, 89 (2009) 383.

11. R.J.H. Voorhoeve, J.P. Remeika, I. E. Trimble, A.S. Cooper, F.J. Disalvo, P.K. Gallagher, J. Solid State Chemistry, 14 (1975) 395.

12. Selected Powder Diffraction Data, Miner. DBM (1-40), J.C.P.D.S., Swarthmore, PA, 1974-1992.

13. K. Zhou, H. Chen, Q. Tian, Z. Hao, D. Shen, X. Xu, J. Molec. Catal. A: Chemical, 189 (2002) 225.

14. F. Gaillard, J.-P. Joly, N. Li, A. Boréave, J.-P. Deloume, J. Sol. State lonics, 179 (2008) 941.

15. F. Gaillard, J.-P. Joly, A.Boréave, P. Vernoux, J.-P. Deloume, Appl. Surf. Sci., 253 (2007) 5876.

16. T. Seiyama, in: L.G. Tejuca, J.L.G.Fierro (Eds.), Properties and Applications of Perovskite-Type Oxides, M. Dekker, New York, 1993, p.215.

17. Y. Teraoka, H.M. Zhang, N. Yamazoe, Chem. Lett., (1985) 1367.

18. Y. Teraoka, M. Yoshimatsu, N. Yamazoe, T. Seiyama, Chem. Lett., (1984) 893.

19. I. Rossetti, L. Forni, Applied catalysis B: Environmental, 33 (2001) 345.

20. S. Utsumi, F.E. Vallejos-Burgos, C.M. Campos, X. Garcìa, A.L. Gordon, G. Pecchi, L.R. Radovic, Catal. Today, 123 (2007) 208.

21. J. Cihlar, D. DelFavero, J. Cihlar Jr., A. Buchal, J. Van herle, J. Europ. Ceram. Soc., 26 (2006) 2999.

22. R. Spinicci, A. Tofanari, A. Delmastro, D. Mazza, S. Ronchetti, Mater. Chem. and Phys., 76 (2002) 20.

23. B. Levasseur, S. Kaliaguine, Appl. Catal. A: General, 343 (2008) 29.

24. G. Pecchi, C. Campos, O. Peña, Mater. Res. Bull., 44 (2009) 846.

25. F.J. Berry, J.F. Marco, X. Ren, J. Solid State Chemistry, 178 (2005) 691.

26. B. Levasseur, S. Kaliaguine, J. Sol. State Chem., 181 (2008) 2953.

27. A. Kaddouri, P.Gelin, N. Dupont, Catalysis Communications, 10 (2009) 1085.

28. L.A. Isupova, I.S. Yakovleva, V.A. Rogov, G.M. Alikina, V.A. Sadykov, Kinet. Catal., 45 (2004) 446.

29. L. Huang, M. Bassir, S. Kaliaguine, Appl. Surf. Sci., 243 (2005) 360.

30. J.P. Dacquin, C. Dujardin, P. Granger, J. Catal., 253 (2008) 37.

31. Y. Wu, L. Luo, React. Kinet. Catal. Lett., 93 (2008) 305.

32. S. Petrović, A. Terlecki-Baričević, Lj. Karanović, P. Kirilov-Stefanov, M. Zdujić, V. Dondur, D. Paneva, I. Mitov, V. Raki, Appl. Catal. B: Environmental, 79 (2008) 186. 
TABLE 1: Catalyst composition and main physical-chemical properties. $T_{0}=$ onset temperature of methane conversion; $T_{50}=$ temperature at which $50 \%$ methane conversion was reached.

\begin{tabular}{|c|c|c|c|c|}
\hline Catalyst & $\mathrm{SSA}, \mathrm{m}^{2} / \mathrm{g}$ & Particle size, $\mathrm{nm}$ & $\mathrm{T}_{0}\left({ }^{\circ} \mathrm{C}\right)$ & $\mathrm{T}_{50}\left({ }^{\circ} \mathrm{C}\right)$ \\
\hline $\mathrm{LaMnO}_{3}$ & 56 & $35-40$ & 262 & 435 \\
\hline $\mathrm{LaCoO}_{3}$ & 43 & - & 250 & 449 \\
\hline $\mathrm{LaFeO}_{3}$ & $38^{*}$ & - & 273 & 495 \\
\hline $\mathrm{La}_{0.9} \mathrm{Sr}_{0.1} \mathrm{MnO}_{3}$ & 51 & $25-35$ & 270 & 419 \\
\hline $\mathrm{La}_{0.8} \mathrm{Sr}_{0.2} \mathrm{MnO}_{3}$ & 70 & $25-60$ & 260 & 434 \\
\hline $\mathrm{La}_{0.9} \mathrm{Ce}_{0.1} \mathrm{MnO}_{3}$ & 84 & $30-45$ & 252 & 433 \\
\hline $\mathrm{La}_{0.9} \mathrm{Ce}_{0.1} \mathrm{MnO}_{3} \_0.4^{* *}$ & 61 & $35-60$ & - & - \\
\hline $\mathrm{La}_{0.9} \mathrm{Sr}_{0.1} \mathrm{CoO}_{3}$ & 52 & $20-60$ & 243 & 453 \\
\hline $\mathrm{La}_{0.9} \mathrm{Ce}_{0.1} \mathrm{CoO}_{3}$ & 62 & - & 262 & 447 \\
\hline $0.5 \% \mathrm{Pt} / \mathrm{LaMnO}{ }_{3}$ & 63 & ca. 40 & 255 & 426 \\
\hline $0.5 \% \mathrm{Pt} / \mathrm{LaMnO}{ }_{3 \_} 0.4^{\star *}$ & 58 & ca. 45 & - & - \\
\hline $0.5 \% \mathrm{Pt} / \mathrm{LaCoO}_{3}$ & 58 & ca. 50 & 262 & 435 \\
\hline $0.5 \% \mathrm{Pd} / \mathrm{LaMnO}_{3}$ & 53 & $30-35$ & 262 & 445 \\
\hline $0.5 \% \mathrm{Pd} / \mathrm{LaCoO}_{3}$ & 54 & - & 270 & 441 \\
\hline $0.5 \% \mathrm{Pd} / \mathrm{LaFeO}_{3}$ & 42 & - & - & - \\
\hline $0.5 \% \mathrm{Pd} / \mathrm{LaCo}_{0.1} \mathrm{Fe}_{0.9} \mathrm{O}_{3}$ & 47 & - & - & - \\
\hline $0.5 \% \mathrm{Pd} / \mathrm{LaCo}_{0.9} \mathrm{Fe}_{0.1} \mathrm{O}_{3}$ & 45 & - & - & - \\
\hline
\end{tabular}

${ }^{*}$ After calcination at $800^{\circ} \mathrm{C}$

** Prepared by setting a 0.4 bar pressure drop across the nozzle 


\section{FIGURE CAPTIONS}

Fig.1: Typical examples of SEM micrograph: a) sample $0.5 \% \mathrm{Pd} / \mathrm{LaMnO}_{3}$; b) sample $\mathrm{LaCoO}_{3}$

Fig.2: TGA pattern (weight loss $\%$ and its derivative) of sample $\mathrm{LaCoO}_{3}$.

Fig.3: XRD patterns of selected FP-prepared perovskites.

Fig.4: TPD-MS of pre-adsorbed oxygen: $\mathrm{LaMnO}_{3}$ (dotted line), $\mathrm{La}_{0.9} \mathrm{Sr}_{0.1} \mathrm{MnO}_{3}$ (thick grey line), $\mathrm{La}_{0.8} \mathrm{Sr}_{0.2} \mathrm{MnO}_{3}$ (thin grey line), $\mathrm{La}_{0.9} \mathrm{Ce}_{0.1} \mathrm{MnO}_{3}$ (thick black line).

Fig.5: TPR-MS patterns of: a) $\mathrm{LaMnO}_{3}$ (black, full line), $\mathrm{LaFeO}_{3}$ (thick grey line), $\mathrm{LaCoO}_{3}$ (black, dotted line); b) $\mathrm{LaCoO}_{3}$ (black, dotted line), $\mathrm{LaCoO}_{3}+0.5$ wt\% $\mathrm{Pd}$ (black, full line), $\mathrm{LaCo}_{0.9} \mathrm{Fe}_{0.1} \mathrm{O}_{3}+0.5 \mathrm{wt} \% \mathrm{Pd}$ (thick grey line).

Fig.6: TPR-MS patterns of: a) $\mathrm{LaCoO}_{3}$ (black, dotted line), $\mathrm{La}_{0.9} \mathrm{Ce}_{0.1} \mathrm{CoO}_{3}$ (black, full line), $\mathrm{La}_{0.9} \mathrm{Sr}_{0.1} \mathrm{CoO}_{3}$ (thick grey line); b) $\mathrm{LaMnO}_{3}$ (black, dotted line), $\mathrm{La}_{0.9} \mathrm{Ce}_{0.1} \mathrm{MnO}_{3}$ (black, full line), $\mathrm{La}_{0.9} \mathrm{Sr}_{0.1} \mathrm{MnO}_{3}$ (thick grey line), $\mathrm{La}_{0.8} \mathrm{Sr}_{0.2} \mathrm{MnO}_{3}$ (thick black line).

Fig.7: TPR-TCD patterns elaboration of $\mathrm{La}_{0.9} \mathrm{Sr}_{0.1} \mathrm{CoO}_{3}$ : experimental data (thick grey line) and fitting curve (black line).

Fig.8: Total amount of oxygen titrated by TPR-TCD vs. $T_{50}$ : a) manganites, b) cobaltites. 
Fig.1a

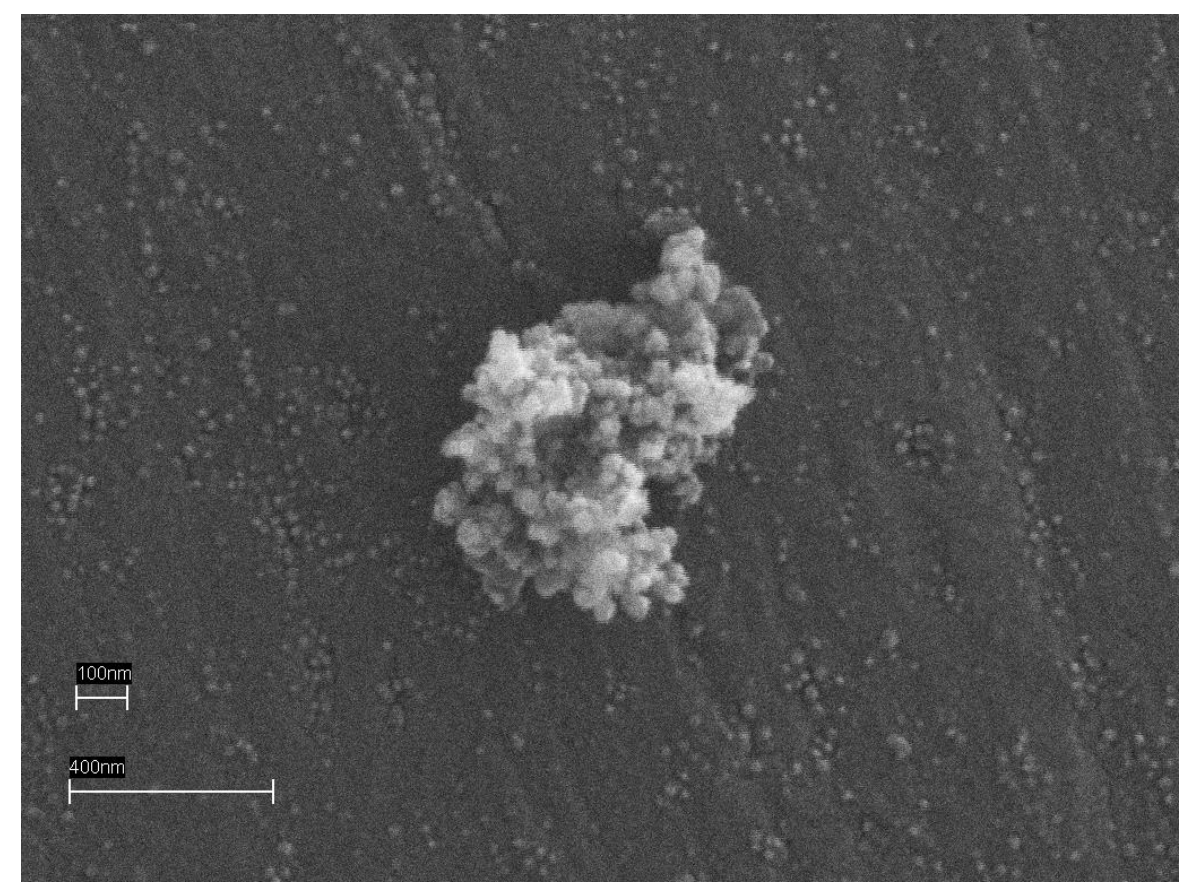

Fig.1b

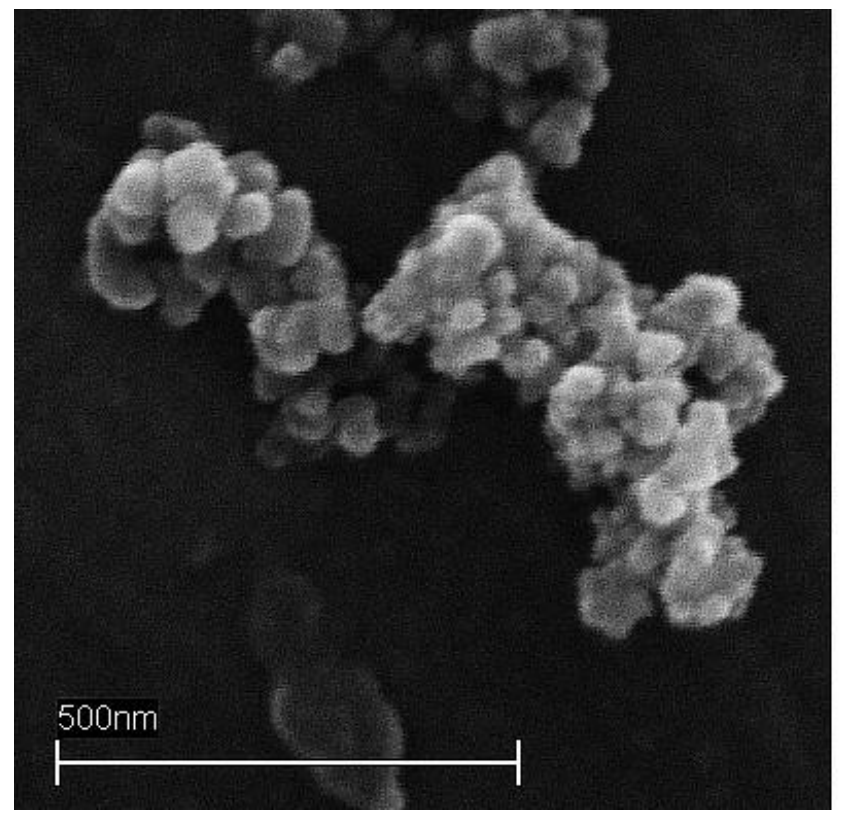


Fig.2

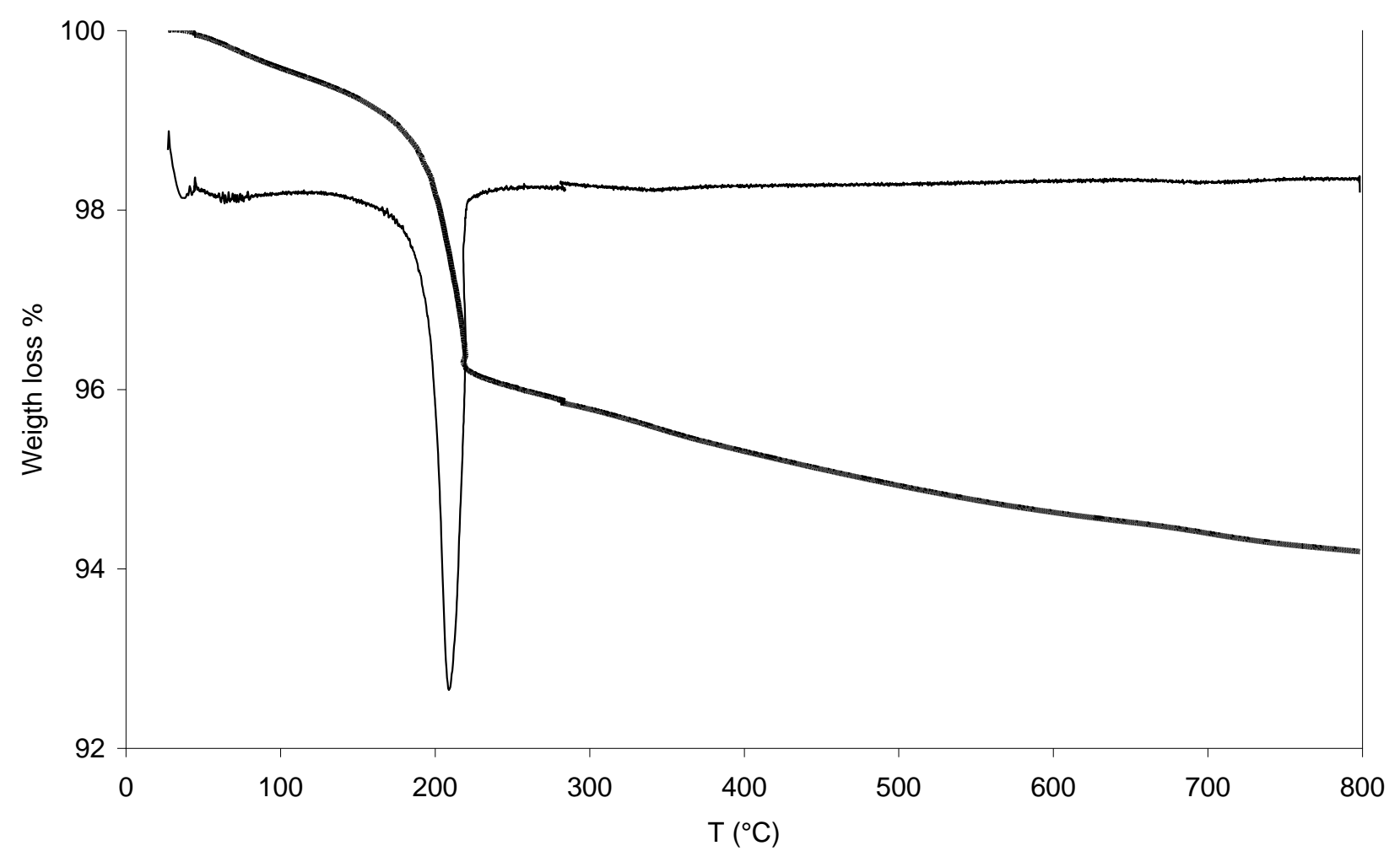

Fig.3

a)

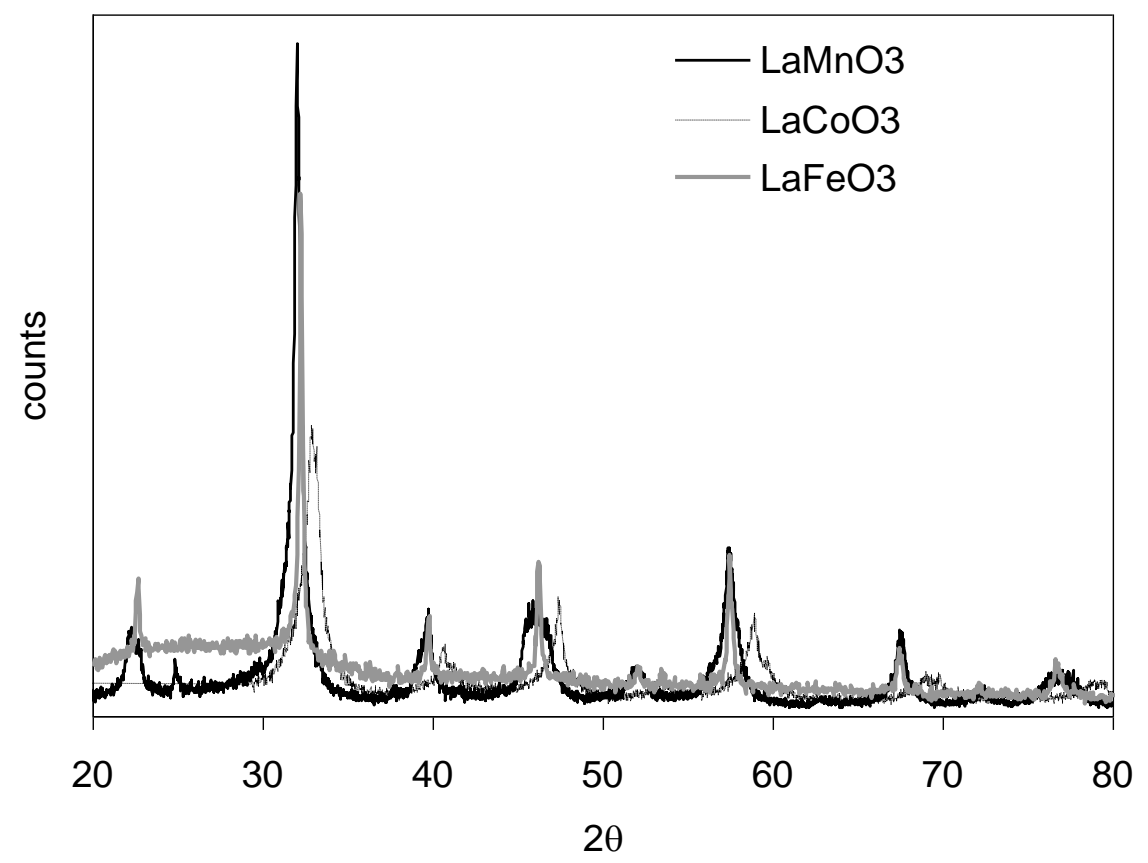


b)

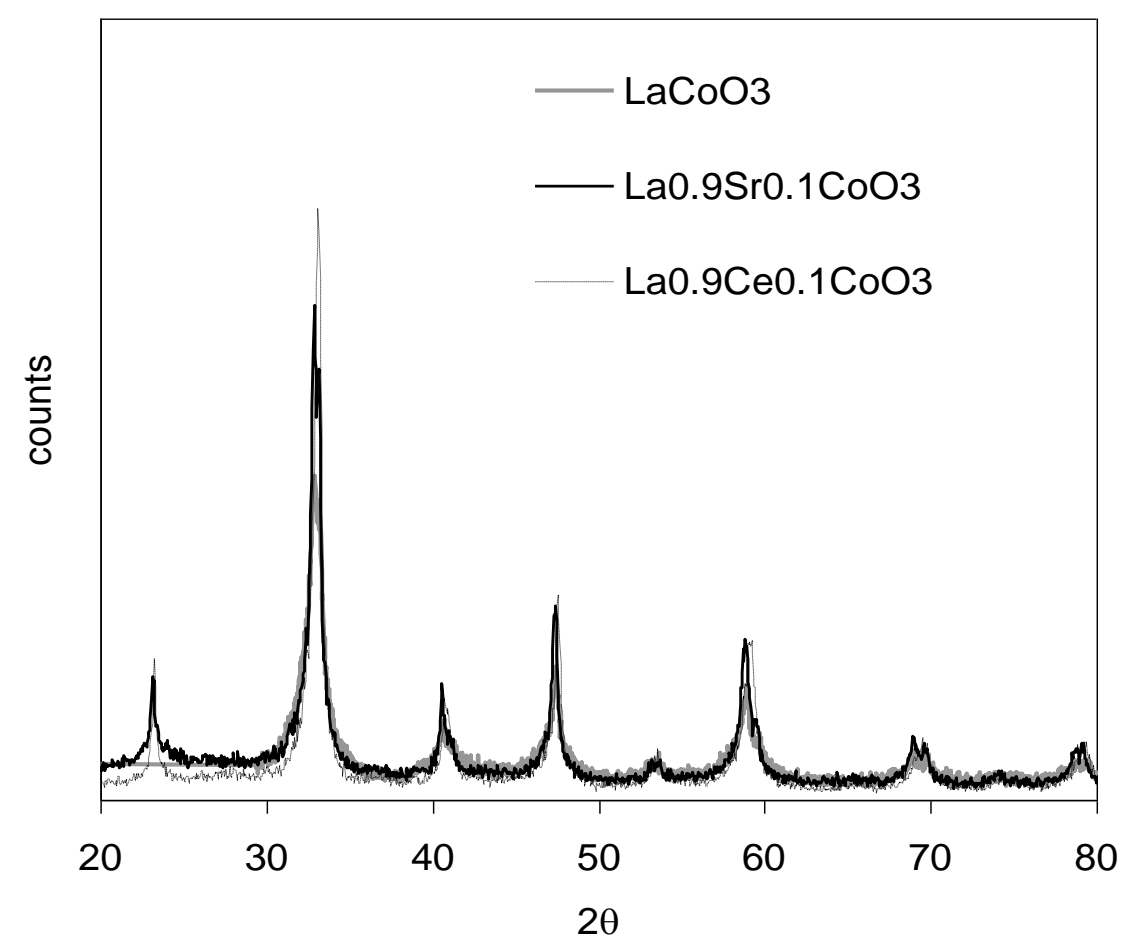

c) 


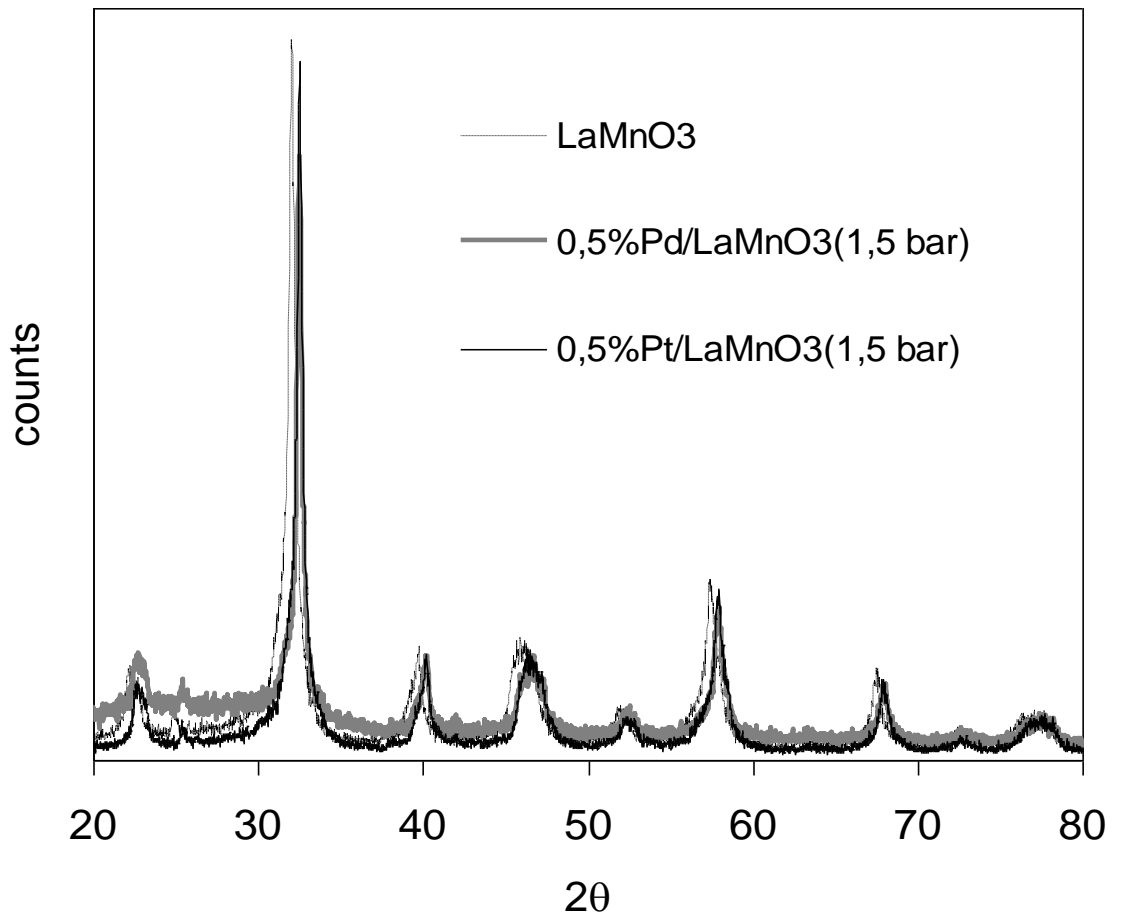


Fig. 4

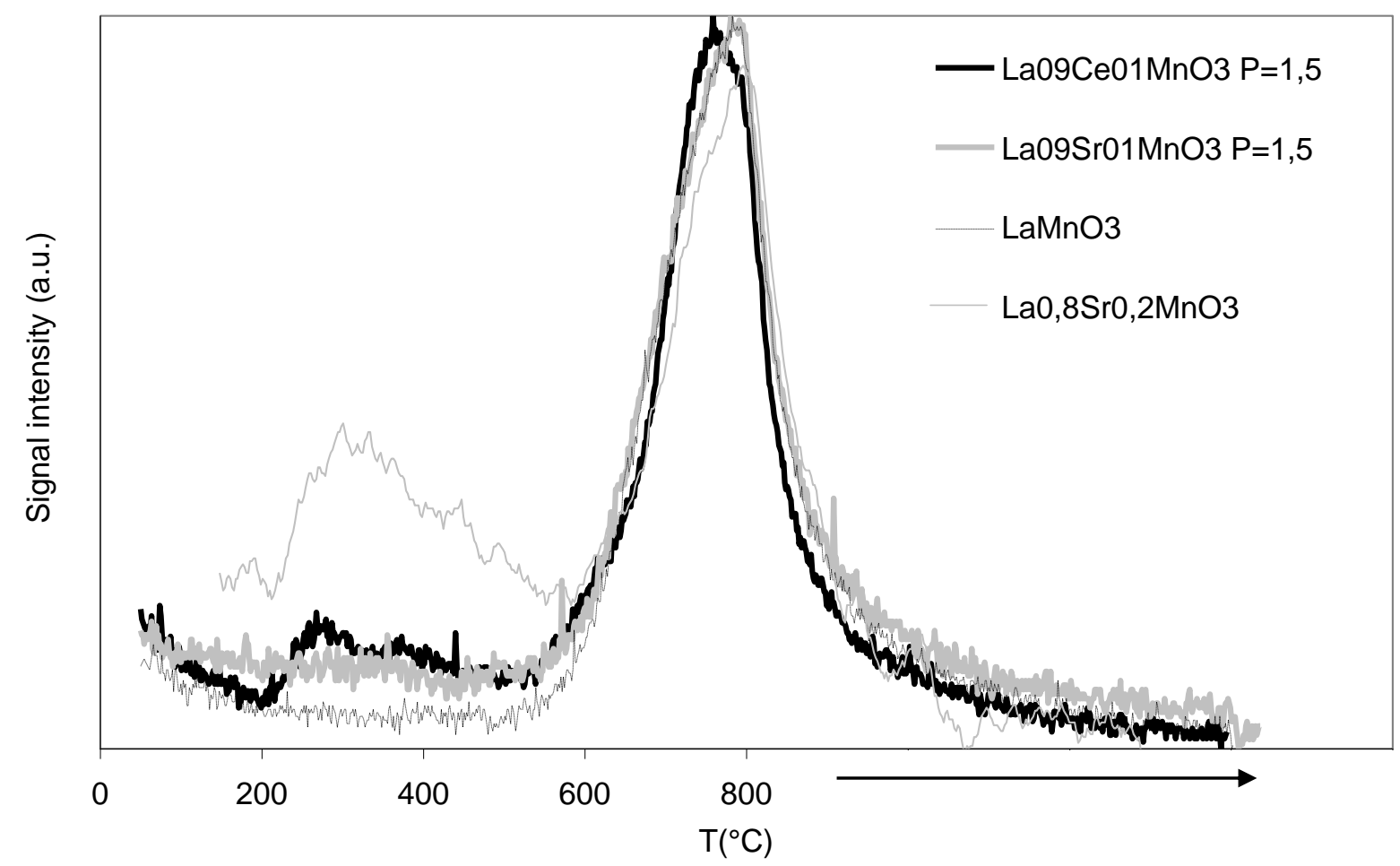


Fig. 5

a)

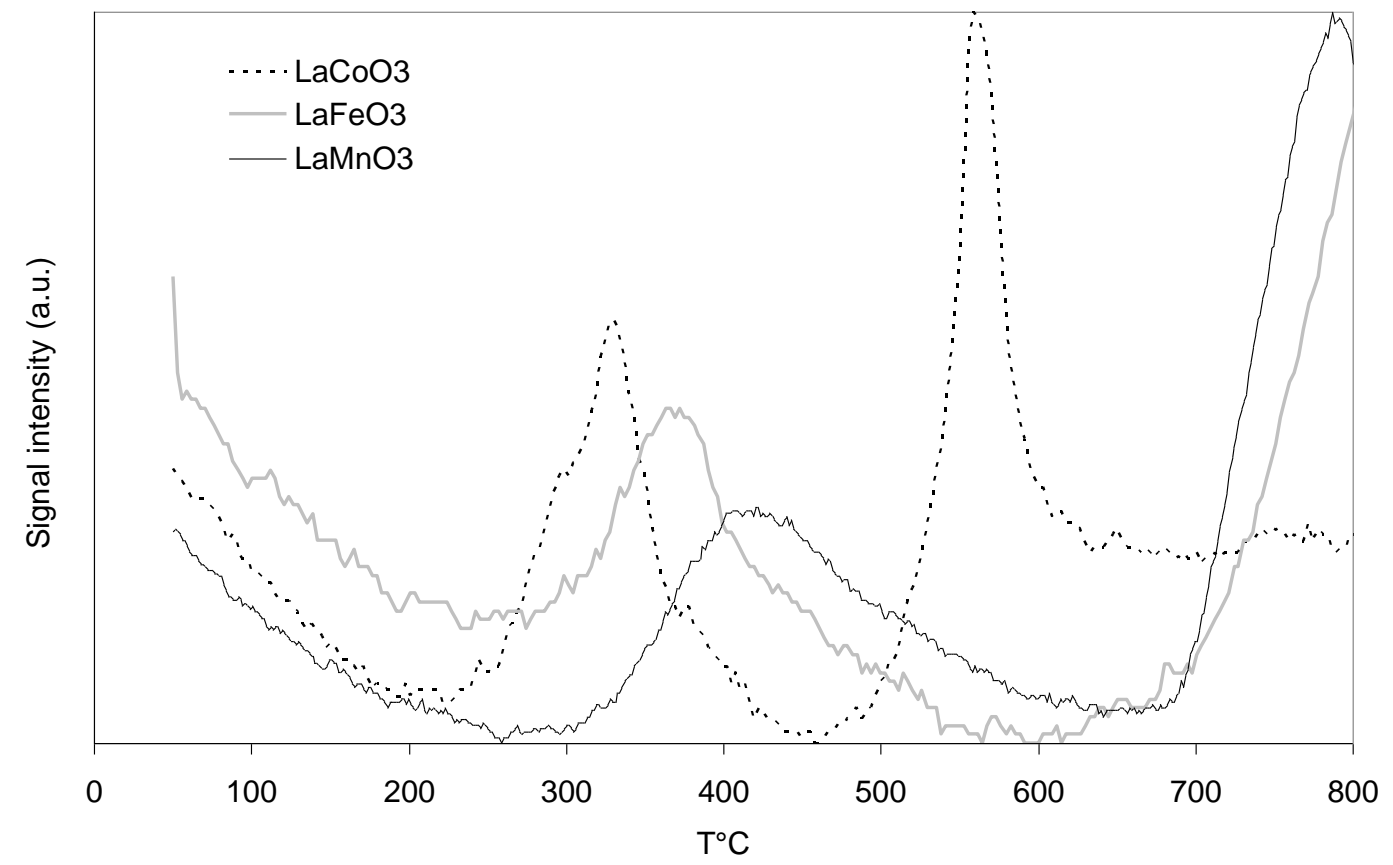

b)

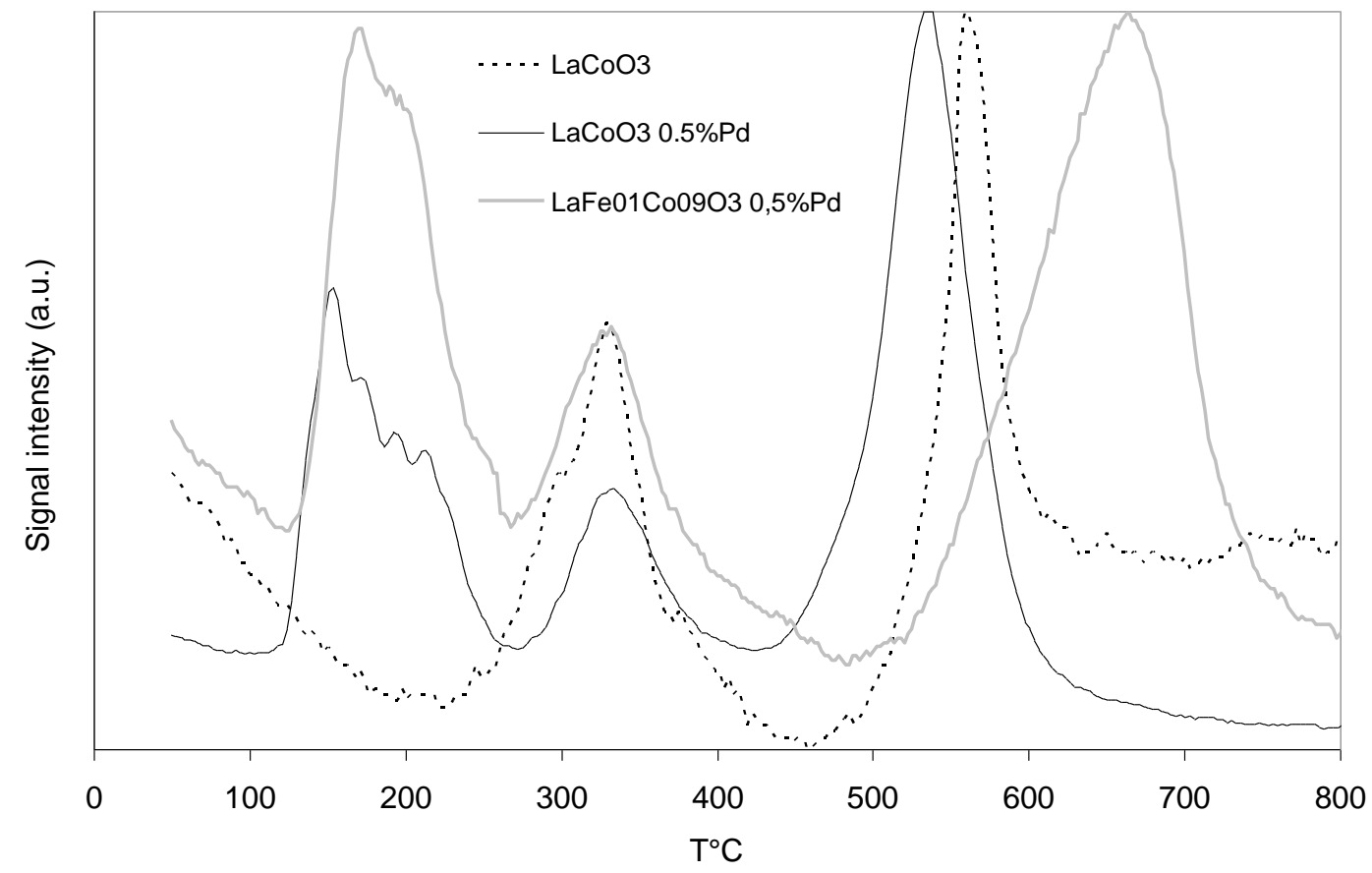


Fig. 6

a)

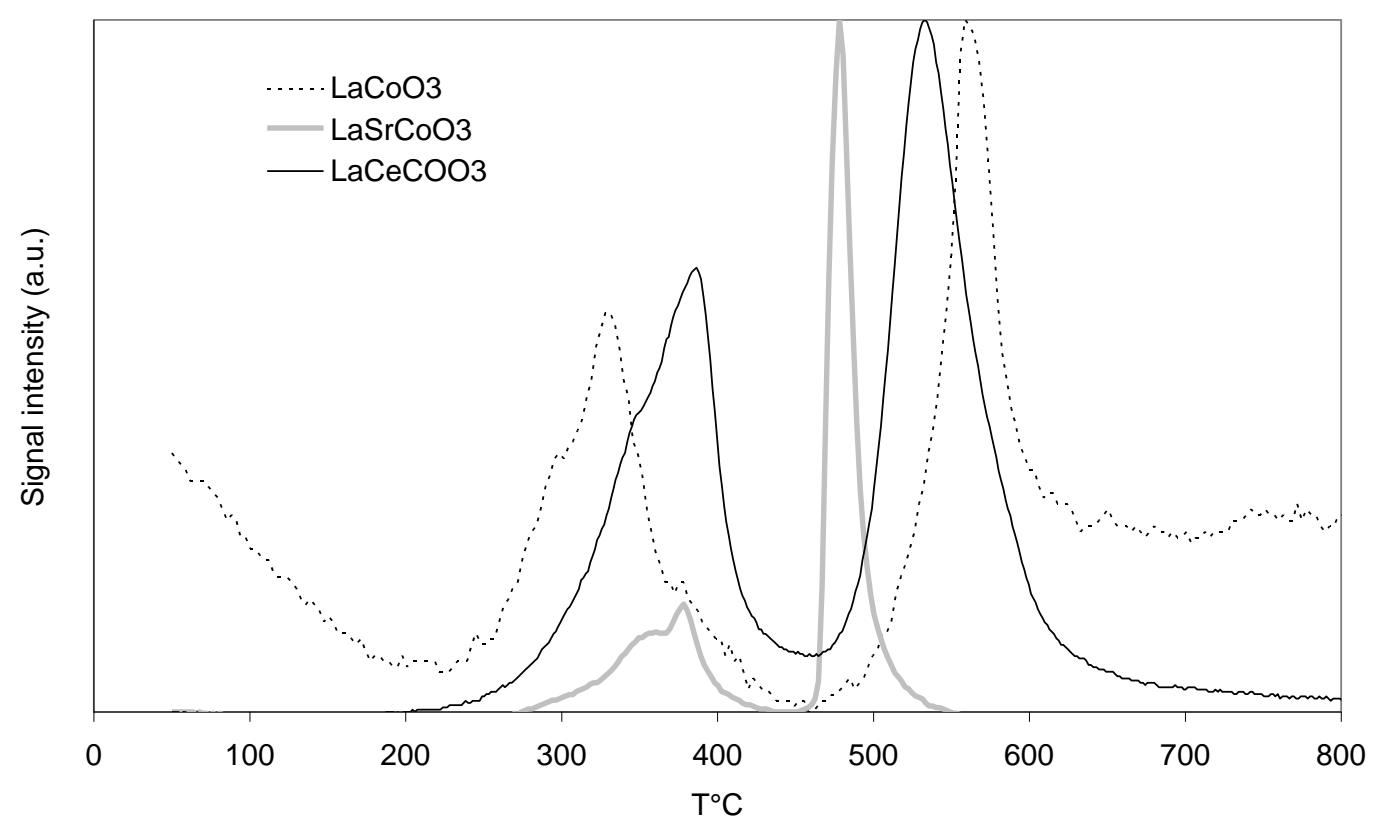

b)

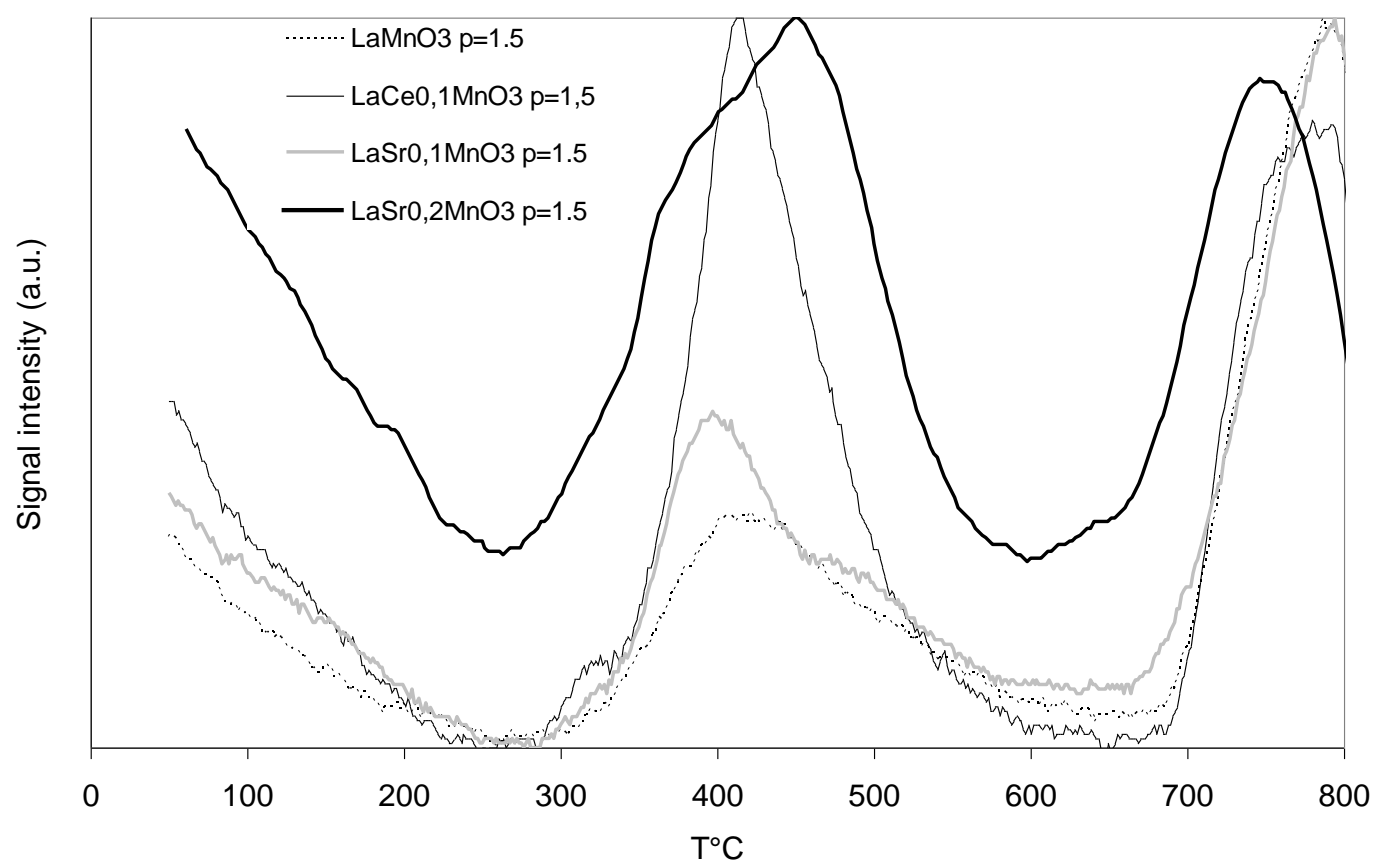


Fig. 7
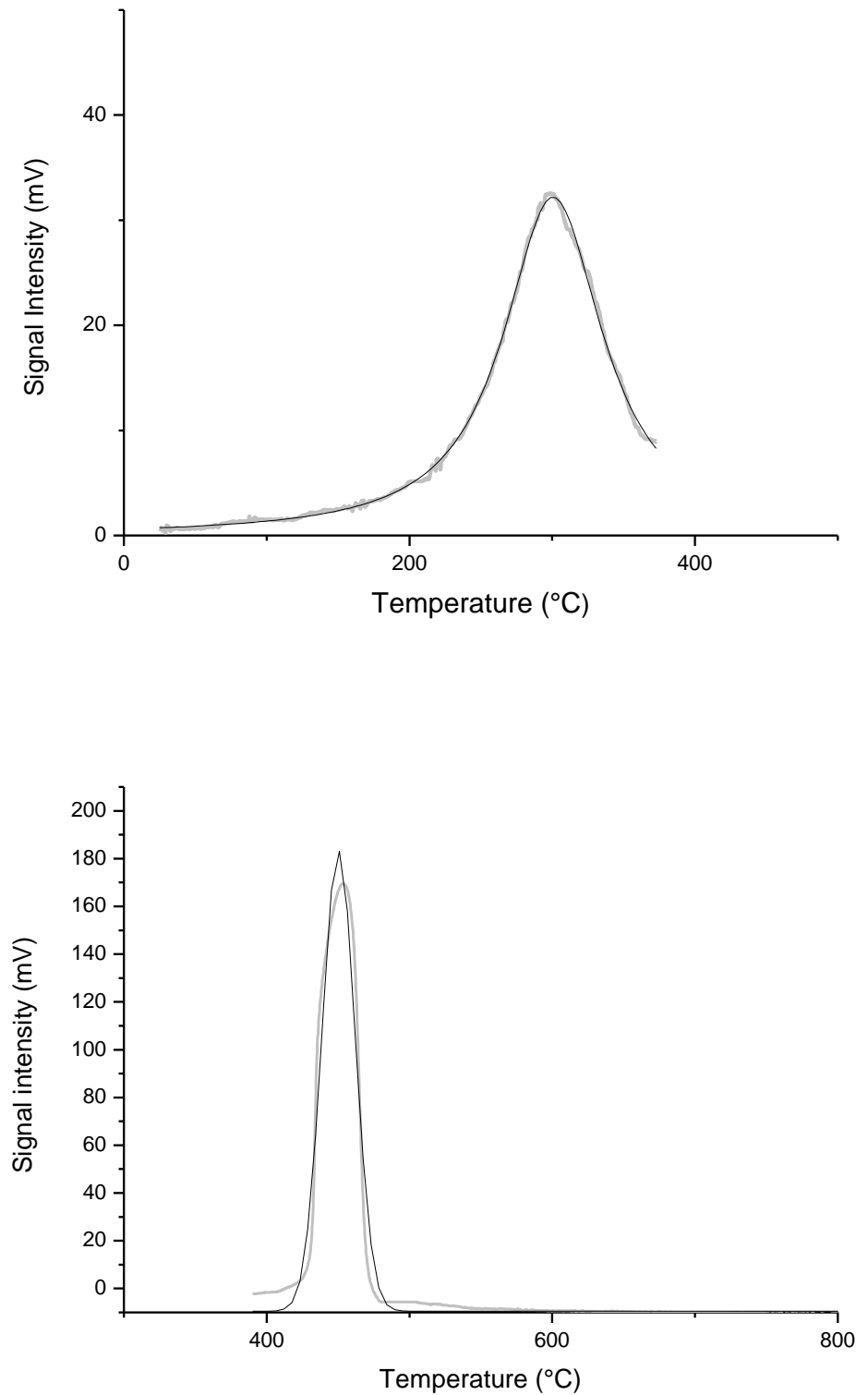
Fig. 8

a)

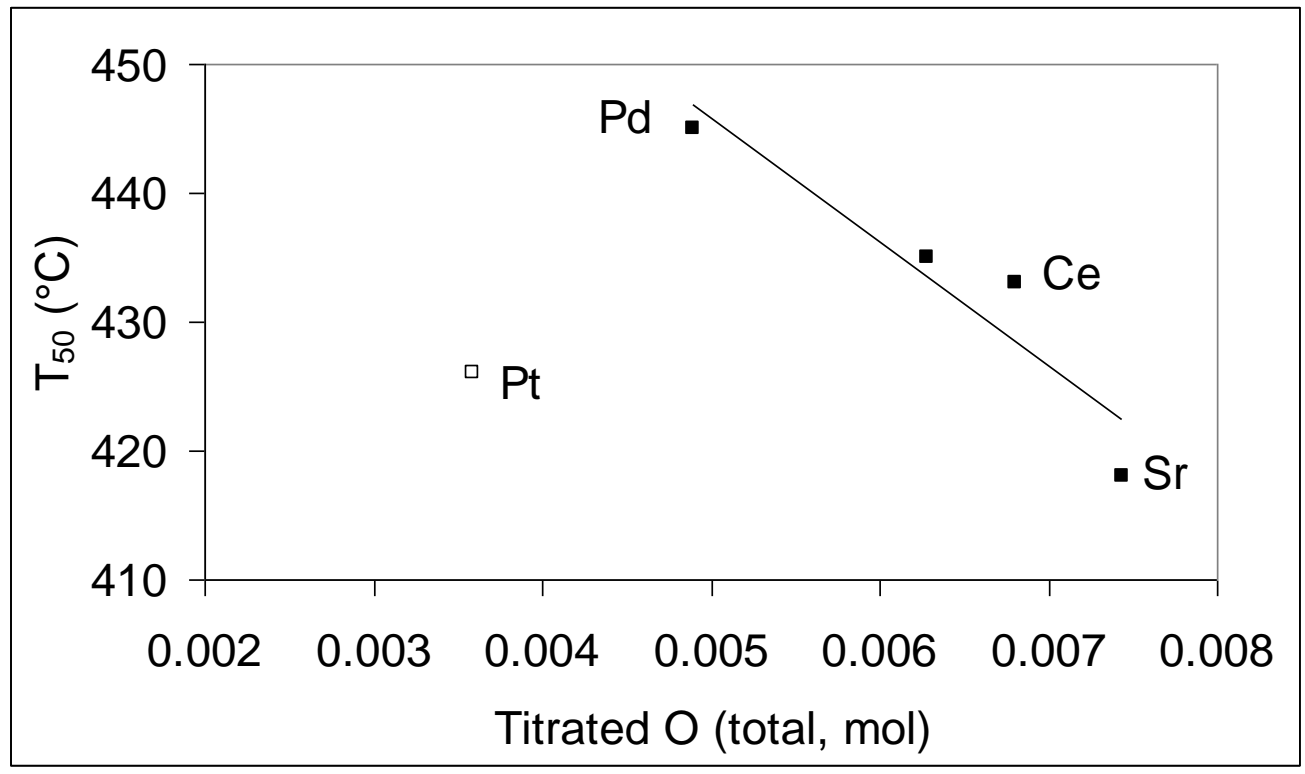

b)

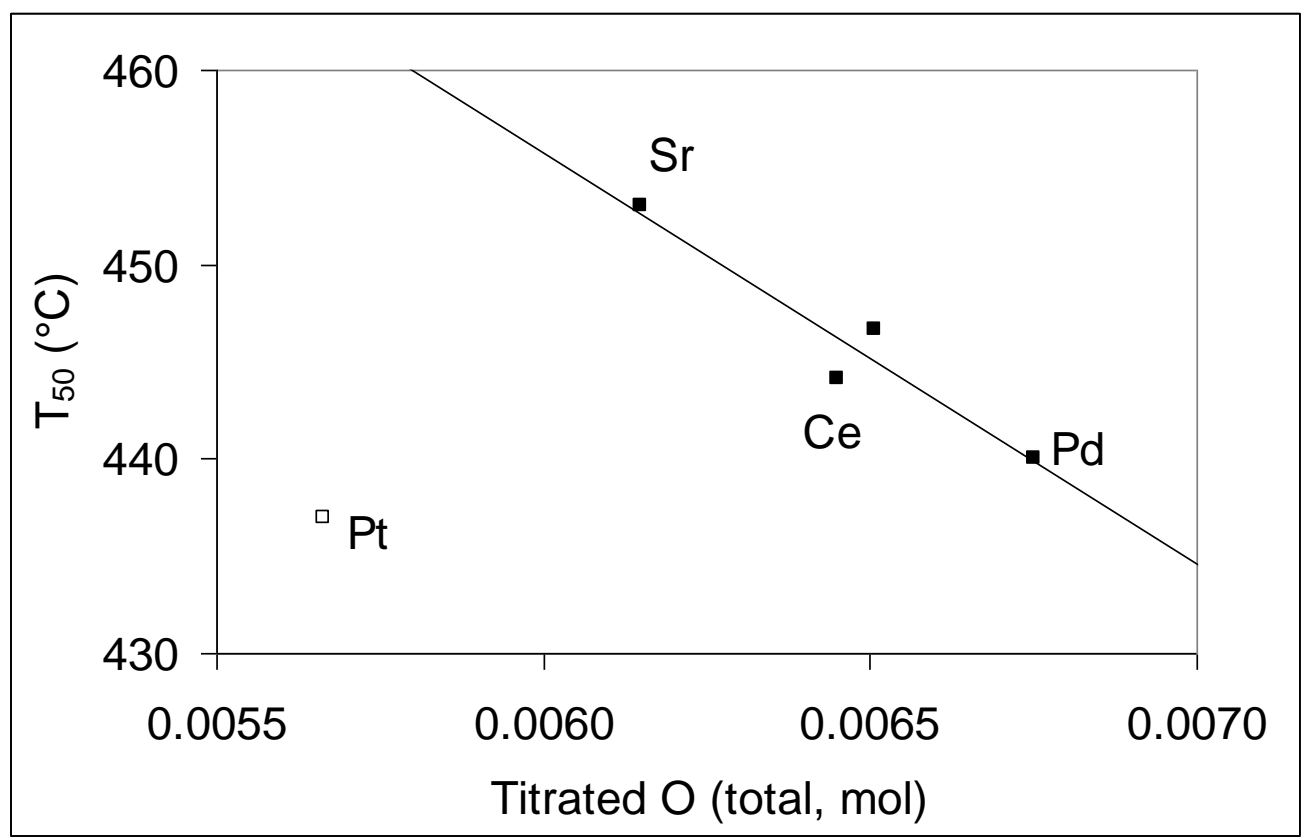

